\title{
Bridging Pragmatic Gap in Translation Process through Developing Pragmatic Awareness
}

\author{
Vahid Rafieyan \\ International College of Liberal Arts, Yamanashi Gakuin University \\ Kofu, Yamanashi, Japan \\ E-mail: rafieyanv@ygu.ac.jp
}

Received: June 11, 2016 Accepted: June 27, 2016 Published: June 28, 2016

doi:10.5296/jsel.v4i1.9667 URL: http://dx.doi.org/10.5296/jsel.v4i1.9667

\begin{abstract}
In order for the translator to be able to translate the source text into the target language in a relevant way, the strata of the translated text through which relevance can be obtained (pragmatic, pragmatic-semantic, and semantic strata) should be equalized to that of the source text (Li \& Luo, 2004). The translator can achieve this by raising his/her awareness of the source and target language pragmatic perspectives. To investigate the actual effect of developing knowledge of pragmatic perspectives of the source language and the target language on the quality of translation of culture-bound texts, the current study was conducted on 64 Iranian undergraduate students of English translation. The study consisted of three phases: 1) administering a culture-bound text to be translated by all participants, 2) dividing participants into two groups: one merely receiving translation exercises while the other receiving metapragmatic discussions of the pragmatic perspectives of the source language along with translation exercises, and 3) assessing the translation quality of both groups immediately and two months following the treatment. The study revealed the significant positive effect of pragmatic instruction on improving the quality of translation of culture-bound texts and maintaining the obtained knowledge. The pedagogical implications of the findings suggested incorporating the pragmalinguistic and sociopragmatic perspectives of the source language and their distinctions with the pragmalinguistic and sociopragmatic perspectives of the target language into translation classes as an integral part of translation classes.
\end{abstract}

Keywords: Implicatures, Pragmatic Instruction, Pragmalinguistics, Sociopragmatics, Translation Quality 


\section{Introduction}

The validity of translation depends on the level at which the intention of speaker/writer can satisfy the expectation of the hearer/reader (Zhao, 1990). In order for the translator to be able to translate the source text into the target language in a relevant way, the strata of the translated text through which relevance can be obtained (pragmatic, pragmatic-semantic, and semantic strata) should be equalized to that of the source text (Li \& Luo, 2004). Translation is a communicative process which involves three parties: the writer of the source text, the translator, and the reader of the target text. As these parties are exposed to distinct cultural and physical environments, their cognitive environments or assumptions about the world are diverse (Zixia, 2009). In the translation process, the reader of the target text does not have access to the writer of the source text. Therefore, target language readers have to spend more effort to process the translated text than the source language readers and the target text yields less contextual effects than the source text. Consequently, the relevance of the target text to the target language readers will be weaker than the relevance of the source text to the source language readers. The reason is that the interpretive resemblance of the target text to the source text is normally constrained because of linguistic and cultural obstacles (Zhanggong, 2006). Therefore, the loss of shared cognitive environments by the source language writer and the target language reader due to cultural differences might restrict target language reader's interpretation of the source language writer's intended meaning. In this situation, the translator needs to broaden his/her cognitive environment or context and provide the reader of the target language with more contextual information by explicating the contextual implication (implied information in the text) in order to bridge the gap between the writer's intention and the reader's expectation and make the translated text optimally relevant to the target language reader (Zhanggong, 2006; Zixia, 2009). This requires the translator to be familiar with the pragmalinguistic and sociopragmatic perspectives of the source language and the target language. This requirement can be fulfilled through pragmatic instruction.

Studies on the translation of culture-bound texts conducted so far have predominantly focused on the quality of translation of pragmatic perspectives of the source language into the target language with no reference to the effect of pragmatic instruction on the development of quality of translators' translation of source language pragmatic perspectives. In one of these studies, Shehab (2004) investigated some major problems which translators may encounter when they translate Arabic utterances containing implicatures into English. The study was conducted by means of a translation task which consisted of a series of underlined Arabic implicatures in their original contexts. Participants of the study, who were a group of postgraduate students of English translation at a university in Palestine, were asked to translate only the underlined implicatures. The analysis of the translated works revealed that in their attempt to translate Arabic implicatures, translation students, more often than not, adopted literal translation where functional or ideational translation should be used. The study also showed that translation students failed to identify the precise meaning intended by the Arabic implicatures and thus failed to convey the accurate meaning to the target language. Bruti (2006) was the other researcher who investigated the extent to which the translation of implicit compliments can be successful with the addressees and whether the chosen 
translation can be considered appropriate for the target language and culture or not. The corpus of analysis was made up of various British and American movies that had been distributed on DVD. The findings of the study suggested that implicit compliments can be successful in Italian subtitles when the original wording is skillfully reproduced so as to involve addressee in a cooperative decoding task of contributing meaning to the speaker's utterance. Otherwise, if something is expunged, the effect might turn out to be scarcely convincing, especially in a language that tends to favor exaggerated forms of approval. In another study, Hassani-Laharomi (2013) compared the translation strategies used in translating conversational implicatures of English plays into Persian by translators before and after Islamic Revolution of Iran. Two English plays and their translations both before and after Islamic Revolution of Iran were selected as the corpus of the study. The results of the investigation showed that in the pre-revolution era, translators had a low tendency to explicate the implied meaning and they subjected themselves to the style and linguistic perspectives of the source language. The same results were yielded regarding the versions translated after Islamic Revolution of Iran. However, in the post-revolution era, translators' tendency to preserve the implicatures decreased. Most recently, Rafieyan (2016) investigated the relationship between translation students' level of pragmatic comprehension ability and the quality of their translations of source language implicatures. Participants of the study were a group of Iranian undergraduate students of English at a university in Iran. Data were collected through a multiple-choice pragmatic comprehension test adopted from Taguchi (2007, 2008, 2012) and a culture-bound text containing some American implicatures adopted from recent news on VOA. The analysis of Pearson product-moment correlation coefficient revealed that ability to comprehend pragmatically implied meanings is a strong predictor of quality of translation of source language implicatures.

The studies conducted so far have mostly explored the role of possessing knowledge of pragmatic competence in the quality of translation of source language pragmatic perspectives. There is, however, a dearth of research over investigating whether developing this pragmatic competence in translators through familiarizing them with the pragmatingustic and sociopragmatic perspectives of the source and target languages can improve the quality of the translation of texts which reflect the sociolinguistic and sociocultural perspectives of the source language community or not. In this respect, the current study seeks to investigate the effect of pragmatic instruction on the quality of translation of culture-bound texts. Therefore, the research question to be addressed in the current study is:

To what extent does pragmatic instruction affect the quality of translation of culture-bound texts?

Accordingly the null hypothesis is:

Pragmatic instruction has no effect on the quality of translation of culture-bound texts.

\section{Methodology}

\subsection{Participants}

Participants of the study consisted of 64 Iranian undergraduate students of English translation 
from two intact classes at a university in Iran. The participants were all at the last semester of their studies; thus, they had passed the majority of linguistic and translation courses and were consequently considered to possess a high level of linguistic and translation ability. None of the participants had previously visited or lived in an English speaking country; therefore, they had not had the opportunity to be directly exposed to source language pragmalinguistic and sociopragmatic perspectives or have contact with source language speakers to be able to develop their pragmatic competence defined as "the ability to use language effectively in order to achieve a specific purpose and to understand language in context" (Thomas, 1983: 92). Among all participants, 28 were males and 34 were females. Their ages ranged from 22 to 30 with a mean age of 22.8 .

\subsection{Instruments}

The instruments used to collect data consisted of three texts flooded with cultural perspectives of the United States used as pre-test, post-test, and follow-up test. The texts contained some excerpts of news adopted from Voice of America (VOA) which is the official external broadcast institution of the United States federal government. The criterion for the selection of the news excerpts for each text was the inclusion of abundant American implicatures. The researcher carefully reviewed current news on VOA website and selected excerpts which contained the highest level of implicatures (around 12 to 15 implicatures in each text). Moreover, to ensure that the translators do their best to present a translation to the best of their knowledge, the texts were kept within a page limit (around 250 to 280 words in each text) to avoid making the translation task tedious. Also, to make sure that all three texts have the same level of difficulty, they were roughly kept at the same length and had roughly the same number of American implicatures.

To assess the validity of the culture-bound texts, content-related evidence of validity was used. The researcher wrote out the definition of what he wanted to measure and then gave this definition, along with the culture-bound texts and a description of the intended sample, to two professors at a university in Iran who were experts in the field of translation. The judges confirmed that the content and format was consistent with the definition of the variable and the sample of objects to be measured (Fraenkel et al., 2012). To assess the reliability of the culture-bound texts, a pilot study was conducted over 32 nonparticipant Iranian senior undergraduate students of English translation at a university in Iran. The reliability coefficient of the culture-bound texts used as pre-test, post-test, and follow-up test assessed through Cronbach's alpha was respectively $0.82,0.78$, and 0.80 .

\subsection{Procedure}

At the beginning of the fall semester of the academic year 2015/2016, the culture-bound text used as pre-test was administered to all translation students participating in the study to be translated. Following the completion of the translation task, participants in one of the classes were assigned to the experimental group (30 participants) and participants of the other class were assigned to the control group (34 participants). Metapragmatic discussions of the pragmalinguistic and sociopragmatic perspectives of the United States along with translation exercises focusing on techniques in appropriate rendering of implied meanings of the source 
language implicatures into the target language were incorporated into the class activities of the experimental group whereas regular translation activities with no reference to the pragmalinguistic and sociopragmatic perspectives of the United States were conducted for the participants in the control group. Intervention was conducted for the whole semester. Then, respectively immediately and two months following the intervention, the culture-bound texts designed for post-test and follow-up test were administered to all participants in both groups to be translated. During each translation test as pre-test, post-test, and follow-up test, participants were given ample time to render a high quality of translation of culture-bound text to the best of their knowledge and were allowed to use any types of dictionaries they wished to use.

\subsection{Data Analysis}

To measure translation students' quality of translations of culture-bound texts for each test, only the translation of implicatures was considered. In this respect, 1 mark was allocated to translations which poorly rendered the implied meaning of all American implicatures into Persian, 2 marks were allocated to translations which weakly rendered the implied meaning of implicatures into Persian, 3 marks were allocated to translations which strongly rendered the implied meaning of implicatures into Persian, and 4 marks were allocated to translations which optimally rendered the implied meaning of implicatures into Persian. The assessment criterion for assessing the quality of translations of implicatures was based on the principle of Relevance Theory developed by Sperber and Wilson (1986). According to this theory, the translator should try to adjust the degree of relevance in source language and target language by equalizing the pragmatic stratum of the translated text, through which relevance is obtained, with that of the source text. Then the translator should ensure that the target text yields enough contextual effects and does not require the target reader any unnecessary processing effort.

To ensure the reliability of the assessments, the quality of translations were rated by two professors at a university in Iran who were experts in the field of translation. The degree of agreement between the ratings assigned by the two professors was then assessed through Cohen's Kappa which is a measure of inter-rater reliability used to measure agreement between two coders (Saldanha \& O'Brien, 2014). The analysis of Cohen's Kappa would give a value between -1 and +1 . The interpretation of the values obtained through Cohen's Kappa, according to Landis and Koch (1977), are presented in Table 1. The inter-rater reliability assessed for the translations was 0.92 which, according to the guidelines set by Landis and Koch (1977), indicates an almost perfect agreement between the two raters. For cases which received different ratings, the two professors discussed until they reached an agreement.

Table 1. Interpretation of Cohen's Kappa Values

\begin{tabular}{ll}
\hline Values & Interpretation \\
\hline Smaller than 0.00 & Poor Agreement \\
\hline 0.00 to 0.20 & Slight Agreement \\
\hline 0.21 to 0.40 & Fair Agreement \\
\hline
\end{tabular}




\begin{tabular}{ll}
\hline 0.61 to 0.80 & Substantial Agreement \\
\hline 0.81 to 1.00 & Almost Perfect Agreement \\
\hline
\end{tabular}

To measure the effect of pragmatic instruction on the quality of translation of culture-bound texts, mixed between-within subjects analysis of variance, which allows combining between-subjects and within-subjects variables in one analysis (Pallant, 2013), was performed over the ratings assigned to the translations of culture-bound texts used as pre-test, post-test, and follow-up test for the two groups (control group and experimental group). In this respect, both the general effect of pragmatic instruction as a whole (within-subjects effect) and the effect of specific type of intervention, that is, inclusion of source language pragmatic perspectives versus exclusion of source language pragmatic perspectives (between-subjects effect) was considered. Partial eta squared was then used to examine the level of effect of intervention for both within-subjects and between-subjects categories. Partial eta squared can range from 0 to 1 and represents the proportion of variance in the dependent variable (quality of translation of culture-bound texts) that is explained by the independent variable (type of treatment) (Pallant, 2013). Cohen (1988) proposed a set of guidelines to interpret the values of partial eta squared. The guidelines for interpreting the values of eta squared, as proposed by Cohen (1988), are presented in Table 2. Finally, the graphical presentation of the performance of participants in both control and experimental groups on the translation of culture-bound texts used as pre-test, post-test, and follow-up test was provided. All the analysis was performed using Statistical Package for Social Sciences (SPSS) software, version 22.

Table 2. Interpretation of Partial Eta Squared Values

\begin{tabular}{ll}
\hline Value & Effect Size \\
\hline 0.01 & Small Effect \\
\hline 0.06 & Moderate Effect \\
\hline 0.14 & Large Effect \\
\hline
\end{tabular}

\section{Results}

Table 3 presents the results of the descriptive analysis of the data. The descriptive analysis presented in the table consists of the number of participants in each group as well as the mean and standard deviation obtained for the performance of each group of participants on pre-test, post-test, and follow-up test. According to the descriptive analysis of the data, although the mean score for the performance of translation students in both control and experimental groups on the translation of culture-bound text enhanced in post-test and follow-up test, the mean score obtained by translation students in the experimental group was higher than the mean score obtained by translation students in the control group. The mean score by itself, however, does not show whether the difference among the three tests and between the two groups is considered significant or not. To determine whether the difference among mean scores obtained by each group over the three tests is significantly different from one another or not, the results of the analysis of mixed between-within subjects analysis of variance need 
to be observed.

Table 3. Descriptive Analysis of Data

\begin{tabular}{lllll}
\hline & Group of & Number & Mean & Std. Deviation \\
& Participants & & & \\
\hline \multirow{2}{*}{ Pre-test } & Experimental & 30 & 1.73 & 0.583 \\
\cline { 2 - 5 } & Control & 34 & 1.76 & 0.654 \\
\cline { 2 - 5 } & Total & 64 & 1.75 & 0.617 \\
\hline \multirow{2}{*}{ Post-test } & Experimental & 30 & 2.77 & 0.817 \\
\cline { 2 - 5 } & Control & 34 & 1.88 & 0.686 \\
\cline { 2 - 5 } & Total & 64 & 2.30 & 0.867 \\
\cline { 2 - 5 } & Experimental & 30 & 2.80 & 0.761 \\
\cline { 2 - 5 } & Control & 34 & 1.91 & 0.621 \\
\cline { 2 - 5 } & Total & 64 & 2.33 & 0.818 \\
\hline
\end{tabular}

Table 4 presents the results of the main effect for within-subjects variable (Test: pre-test, post-test, follow-up test). To explore the main effect for within-subjects variable, the value of Wilks' Lambda and the associated probability value given in the column labeled Significance (Sig.) needs to be considered. All of the multivariate tests yield the same result; however, the most commonly reported statistic is Wilks' Lambda (Pallant, 2013). A significance value of above $0.05(\mathrm{p}>0.05)$ for Wilks' Lambda indicates a non-significant effect whereas a significance value of equal to or less than $0.05(\mathrm{p} \leq 0.05)$ is indicative of a significant effect (Gravetter \& Wallnau, 2013). In the data obtained in the current study, the value for Wilks' Lambda for Test is 0.259 , with a significance value of 0.000 (which really means $p<0.0005$ ). Because the $\mathrm{p}$ value is less than 0.05 , there is a statistically significant effect for Test. This suggests that there was a change in translation quality across the three different tests. The main effect for Test was significant.

Although a statistically significant difference among the performance of translation students on different tests (pre-test, post-test, and follow-up test) was found, the effect size of this result also needs to be considered to be able to determine the exact size of this difference. In this regard, the value of interest is partial eta squared. The value of partial eta squared obtained for Test in this study is 0.741 . Using the commonly used guidelines proposed by Cohen (1988), this result suggests a very large effect size. Expressed as a percentage, 74.1 percent of variance in the performance of translation students on the quality of translation of culture-bound texts is explained by the treatment they received at different time intervals.

Table 4. Multivariate Tests ${ }^{\mathrm{a}}$

\begin{tabular}{lllccccc}
\hline Effect & & Value & F & $\begin{array}{c}\text { Hypothesis } \\
\text { df }\end{array}$ & $\begin{array}{c}\text { Error } \\
\text { df }\end{array}$ & $\begin{array}{c}\text { Sig. } \\
\text { Partial Eta } \\
\text { Squared }\end{array}$ \\
\hline Test & Pillai's Trace & 0.741 & $87.099^{\mathrm{b}}$ & 2.000 & 61.000 & 0.000 & 0.741 \\
\cline { 2 - 8 } & Wilks' Lambda & 0.259 & $87.099^{\mathrm{b}}$ & 2.000 & 61.000 & 0.000 & 0.741 \\
\cline { 2 - 8 } & Hotelling's Trace & 2.856 & $87.099^{\mathrm{b}}$ & 2.000 & 61.000 & 0.000 & 0.741 \\
\hline
\end{tabular}




$$
\begin{array}{llllllll}
\text { Roy's } & \text { Largest } & 2.856 & 87.099^{\mathrm{b}} & 2.000 & 61.000 & 0.000 & 0.741
\end{array}
$$

Root

\begin{tabular}{llllllll}
\hline Test * Group & Pillai's Trace & 0.635 & $52.983^{\mathrm{b}}$ & 2.000 & 61.000 & 0.000 & 0.635 \\
\cline { 2 - 7 } & Wilks' Lambda & 0.365 & $52.983^{\mathrm{b}}$ & 2.000 & 61.000 & 0.000 & 0.635 \\
\cline { 2 - 7 } & Hotelling's Trace & 1.737 & $52.983^{\mathrm{b}}$ & 2.000 & 61.000 & 0.000 & 0.635 \\
\cline { 2 - 7 } & $\begin{array}{l}\text { Roy's Largest } \\
\text { Root }\end{array}$ & 1.737 & $52.983^{\mathrm{b}}$ & 2.000 & 61.000 & 0.000 & 0.635 \\
\hline
\end{tabular}

a. Design: Intercept + Group

Within Subjects Design: Test

b. Exact statistic

Now that the within-subjects effects have been explored, the main effect for between-subjects variable (type of intervention: inclusion of pragmatic instruction versus exclusion of pragmatic instruction) needs to be considered. The results that need to be considered are in Table 5. In this respect, the significance value across the row labeled Group (variable name for the type of intervention) should be considered. A significance value of above 0.05 ( $\mathrm{p}>$ 0.05 ) for Group indicates a non-significant effect whereas a significance value of equal to or less than $0.05(p \leq 0.05)$ is indicative of a significant effect (Gravetter \& Wallnau, 2013). In the data obtained in the current study, the value for Group is 0.001 . This is less than the alpha level of 0.05 , so the main effect for Group is significant. There was a significant difference in the translation quality for the two groups (those who received pragmatic instruction and those who did not receive pragmatic instruction).

Although a statistically significant difference between the performance of translation students in the two groups (control group and experimental group) was found, the effect size of this result also needs to be considered to be able to determine the exact size of this difference. In this regard, the value of interest is again partial eta squared. The value of partial eta squared obtained for Group in this study is 0.167 which, according to the guidelines proposed by Cohen (1988), indicates a large effect size. Expressed as a percentage, 16.7 percent of variance in the performance of translation students on the quality of translation of culture-bound texts is explained by the type of treatment they received.

Table 5. Tests of Between-Subjects Effects

\begin{tabular}{llccccc}
\hline Source & $\begin{array}{l}\text { Type III } \\
\text { Sum of } \\
\text { Squares }\end{array}$ & df & $\begin{array}{l}\text { Mean } \\
\text { Square }\end{array}$ & F & Sig. & $\begin{array}{c}\text { Partial Eta } \\
\text { Squared }\end{array}$ \\
\hline Intercept & 878.418 & 1 & 878.418 & 678.844 & 0.000 & 0.916 \\
\hline Group & 16.106 & 1 & 16.106 & 12.447 & 0.001 & 0.167 \\
\hline Error & 80.227 & 62 & 1.294 & & & \\
\hline
\end{tabular}

The graphical presentation of the performance of translation students in both control and experimental groups on translating culture-bound texts used as pre-test, post-test, and follow-up test has been depicted in Figure 1. As Figure 1 shows, translation students in both 
groups exhibited a significant improvement in the quality of translation of culture-bound text following a semester-long intervention and maintained the obtained knowledge after two months following the intervention. However, translation students in the experimental group (those who received pragmatic instruction) exhibited a significantly better performance than translation students in the control group (those who did not receive pragmatic instruction).

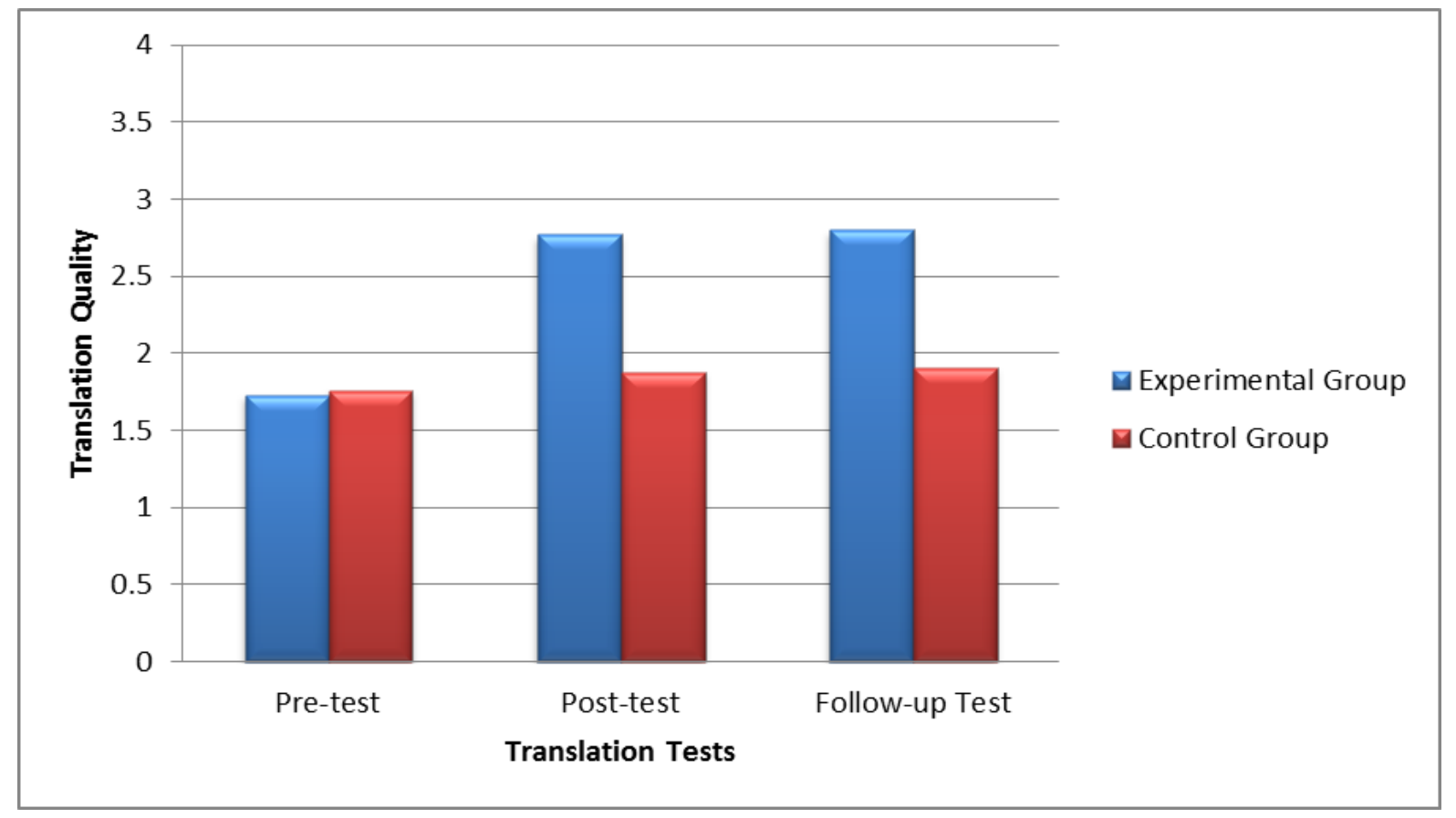

Figure 1. Performance of Participants in Control and Experimental Groups on Pre-test, Post-test, and Follow-up Test

\section{Discussion}

The study found that incorporation of source language pragmatic perspectives into class instruction has a significant impact on improving the quality of translation of culture-bound texts. Translation students who were instructed the pragmatic perspectives of the United States not only improved the quality of their translations of American implicatures to a great extent following intervention and managed to maintain their obtained translation skill even two months following intervention but also exhibited a much better performance than translation students who were not involved in pragmatic instruction. Therefore, the null hypothesis of the study which states that pragmatic instruction has no effect on the quality of translation of culture-bound texts is rejected.

These findings can be explained through Noticing Hypothesis and Relevance Theory. Noticing Hypothesis introduced by Schmidt (1990) states that "people learn about the things that they attend to and do not learn much about the things they do not attend to" (Schmidt, 2001:30). This hypothesis emphasizes that in order to turn input into intake, input needs to be detected in the form of attention and awareness (Schmidt, 1995). Every input has a different value and only the input which is paid attention to and noticed turns into intake and becomes available for effective processing (Schmidt, 1990; 2001). Intake is part of the input which is 
noticed and paid attention to and is transferred into short-term memory and subsequently is integrated into the interlanguage. Interlanguage is a language which is independent from both the language learner's heritage language and the language to be learned (Selinker, 1972). Relevance Theory which was developed by Sperber and Wilson (1986) also deals with two notions: the contextual effects given by a text and the processing effort required to be made by the readers to be able to comprehend the text. The principle of relevance mentions that "everything else being equal, the greater the positive contextual effects achieved by the audience, the greater the relevance of the input to the person processing it; however, everything else being equal, the smaller the processing effort required by the audience to obtain these effects, the greater the relevance of the input to the person processing it" (Rafieyan, 2015b: 26).

According to Bachman's (1990) model of communicative competence, pragmatic competence and grammatical competence are two distinct aspects of communicative competence and a high level of grammatical competence does not lead to a high level of pragmatic competence (Bardovi-Harlig \& Dornyei, 1998; Bardovi-Harlig, 2001; Barron, 2003; Rose, 2005). As pragmatic perspectives of some languages differ significantly, a mere focus on linguistic competence does not lead translation students to notice the pragmalinguistic and sociopragmatic distinctions between the source language and the target language and does not equip them with sufficient knowledge of pragmatic perspectives of the source language to be able to transfer the source language pragmalinguistic and sociopragmatic perspective into the target language in such a way that the translation yields enough contextual effect without requiring the target language reader to put unnecessary processing effort to be able to comprehend the translated text.

In the current study, translation students who received pragmatic instruction managed to develop knowledge of the pragmalinguistic and sociopragmatic perspectives of the source language as well as awareness of the distinctions between the source language and the target language pragmalinguistic and sociopragmatic perspectives. This knowledge and awareness most likely equipped them with the ability to notice and focus on the pragmatic perspectives of the source language text and present them in the target language text in such a way that provides enough contextual effect for the target language reader to be easily comprehended without putting unnecessary processing effort. This knowledge and awareness, however, most probably did not develop in translation students who did not focus on the pragmatic perspectives of the source language during intervention; consequently, they failed to notice them and furnish translated text with enough contextual effects to reduce the processing demand on the part of the target language reader.

The findings obtained in the current study are in line with the findings obtained in the studies conducted by Shehab (2004), Bruti (2006), Hassani-Laharomi (2013), and Rafieyan (2016) who found that knowledge of the source language pragmalinguistic and sociopragmatic perspectives contributes to a great extent to the quality of translation of the source language pragmatic perspectives into the target language. The findings obtained in the current study also support the findings obtained in the studies conducted by Rafieyan et al. (2014a) and Rafieyan et al. (2014c) who found that pragmatic instruction has a significant effect on the 
development of pragmatic competence in language learners.

\section{Conclusion}

The study revealed the significant positive effect of pragmatic instruction on improving the quality of translation of culture-bound texts and maintaining the obtained knowledge. Translation students who were taught the pragmalinguistic and sociopragmatic perspectives of the source language and their distinctions with the pragmalinguistic and sociopragmatic perspectives of the target language managed to present their translation of culture-bound texts at a higher level of quality than language learners who did not receive pragmatic instruction both immediately and after a period of time following intervention. Therefore, teachers of translation courses are advised to incorporate the pragmalinguistic and sociopragmatic perspectives of the source language and their distinctions with the pragmalinguistic and sociopragmatic perspectives of the target language into translation classes as an integral part of the translation classes (Rafieyan et al., 2014a; Rafieyan et al., 2014b; Rafieyan et al., 2014c; Rafieyan, 2015a).

The study was limited in the way that it did not assess the effect of provision of direct exposure to authentic source language pragmalinguistic and sociopragmatic perspectives by providing opportunities for translation students to engage in computer-mediated intercultural communication with source language speakers using technological tools such as synchronous chat and e-mail as well as popular social networks such as Facebook, Skype, LinkedIn, and WhatsApp through telecollaboration which is defined as "institutionalized, electronically mediated intercultural communication under the guidance of a languacultural expert (i.e., a teacher) for the purposes of foreign language learning and the development of intercultural competence" (Belz, 2003, p. 2). Therefore, future studies are recommended to investigate the effect of telecollaborative partnership as compared to pragmatic instruction on the development of pragmatic knowledge in translation students.

\section{Acknowledgement}

The author would like to acknowledge the contribution of Parvaneh Rafieyan.

\section{References}

Bachman, L. F. (1990). Fundamental Considerations in Language Testing. Oxford: Oxford University Press.

Bardovi-Harlig, K., \& Dornyei, B. (1998). Do Language Learners Recognize Pragmatic Violations? Pragmatic versus Grammatical Awareness in Instructed L2 Learning. TESOL Quarterly, 32(2), 233-259. http://dx.doi.org/10.2307/3587583

Bardovi-Harlig, K. (2001). Empirical Evidence of the Need for Instruction in Pragmatics. In K. R. Rose, \& G. Kasper (Eds.), Pragmatics in Language Teaching (pp. 13-32). Cambridge: Cambridge University Press. http://dx.doi.org/10.1017/CBO9781139524797.005

Barron, A. (2003). Acquisition in Interlanguage Pragmatics: Learning How to Do Things with Words in a Study Abroad Context. Amesterdam: Benjamins. http://dx.doi.org/10.1075/pbns.108 


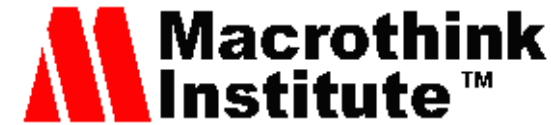

Journal for the Study of English Linguistics

ISSN 2329-7034

2016, Vol. 4, No. 1

Belz, J. A. (2003). From the Special Issue Editor. Language Learning \& Technology, 7(2), $2-5$.

Bruti, S. (2006). Cross-Cultural Pragmatics: The Translation of Implicit Compliments in Subtitles. The Journal of Specialized Translation, 6, 185-197.

Cohen, J. (1988). Statistical Power Analysis for the Behavioral Sciences. Hillsdale, NJ: Lawrence Erlbaum Associates.

Fraenkel, J. R., Wallen, N. E., \& Hyun, H. H. (2012). How to Design and Evaluate Research in Education (8th ed.). New York: McGraw-Hill.

Gravetter, F. J., \& Wallnau, L. B. (2013). Statistics for the Behavioral Sciences. Belmont, C A: Wadsworth Publishing.

Hassani-Laharomi, Z. (2013). Conversational Implicatures in English Plays and Their Persian Translations: A Norm-governed Study. International Journal of Applied Linguistics \& English Literature, 2(5), 51-61. http://dx.doi.org/10.7575/aiac.ijalel.v.2n.5p.51

Landis, J. R., \& Koch, G. G. (1977). The Measurement of Observer Agreement for Categorical Data. Biometrics, 33(1), 159-174. http://dx.doi.org/10.2307/2529310

Li, Y., \& Luo, X. M. (2004). Relevance and Translation. Foreign Language and Foreign Language Teaching, 4, 40-42.

Pallant, J. (2013). SPSS Survival Manual: A Step by Step Guide to Data Analysis Using SPSS Program (5th ed.). Australia: Allen \& Unwin.

Rafieyan, V., Sharafi-Nejad, M., \& Lin, S. E. (2014a). Effect of Pragmatic Instruction on Sustainable Development of Pragmatic Awareness. Journal of Studies in Education, 4(1), 206-218. http://dx.doi.org/10.5296/jse.v4i1.5088

Rafieyan, V., Sharafi-Nejad, M., \& Lin, S. E. (2014b). Effect of Pragmatic Awareness on Comprehension and Production of Conventional Expressions. Theory and Practice in Language Studies, 4(7), 1352-1358. http://dx.doi.org/10.4304/tpls.4.7.1352-1358

Rafieyan, V., Sharafi-Nejad, M., \& Lin, S. E. (2014c). Effect of Form-Focused Pragmatic Instruction on Production of Conventional Expressions. Theory and Practice in Language Studies, 4(8), 586-1592. http://dx.doi.org/10.4304/tpls.4.8.1586-1592

Rafieyan, V. (2015a). Effect of National Cultural Distance as Predictor of Pragmatic Competence on Writing Proficiency. Research on Humanities and Social Sciences, 5(18), 122-129.

Rafieyan, V. (2015b). Effect of Form-Focused Pragmatic Instruction on Development of Pragmatic Comprehension: A Conceptual Framework. International Journal of Learning \& Development, 5(4), 24-39. http://dx.doi.org/10.5296/ijld.v5i4.8349

Rafieyan, V. (2016). Relationship between Pragmatic Comprehension and Translation of Culture-Bound Texts. Journal of Applied Linguistics and Language Research, 3(3), 257-267.

Rose, K. R. (2005). On the Effects of Instruction in Second Language Pragmatics. System, 33(3), 385-399. http://dx.doi.org/10.1016/j.system.2005.06.003

Saldanha, G., \& O’Brien, S. (2014). Research Methodologies in Translation Studies. New York, NY: Routledge. 


\section{Macrothink}

Shehab, E. (2004). The Translatability of Utterances Containing Implicatures from Arabic into English. An-Najah Univ. J. Res. (H. Sc.), 18(2), 628-709.

Schmidt, R. W. (1990). The Role of Consciousness in Second Language Learning. Applied Linguistics, 11(2), 129-158. http://dx.doi.org/10.1093/applin/11.2.129

Schmidt, R. W. (1995). Consciousness and Foreign Language Learning: A Tutorial on the Role of Attention and Awareness in Learning. In R. W. Schmidt (Ed.), Attention and Awareness in Foreign Language Learning (Technical Report No. 9, pp. 1-63). University of Hawaii: Honolulu.

Schmidt, R. W. (2001). Attention. In P. Robinson (Ed.), Cognition and Second Language Instruction (pp. 3-32). Cambridge: Cambridge University Press. http://dx.doi.org/10.1017/CBO9781139524780.003

Selinker, L. (1972). Interlanguage. International Review of Applied Linguistics, 10(2), 209-230. http://dx.doi.org/10.1515/iral.1972.10.1-4.209

Sperber, D., \& Wilson, D. (1986). Relevance: Cognition and Communication. Oxford, UK: Blackwell Publishers Ltd.

Taguchi, N. (2007). Development of Speed and Accuracy in Pragmatic Comprehension in English as a Foreign Language. TESOL Quarterly, 42, 313-338. http://dx.doi.org/10.1002/j.1545-7249.2007.tb00061.x

Taguchi, N. (2008). The Role of Learning Environment in the Development of Pragmatic Comprehension: A Comparison of Gains between EFL and ESL Learners. Studies in Second Language Acquisition, 30, 423-452. http://dx.doi.org/10.1017/S0272263108080716

Taguchi, N. (2012). Context, Individual Differences and Pragmatic Competence. Bristol: Multilingual Matters.

Thomas, J. (1983). Cross Cultural Pragmatic Failure. Applied Linguistics, 4(2), 91-112. http://dx.doi.org/10.1093/applin/4.2.91

Zhao, X. (1990). Taiji zuoqu xitong [The Taiji Composition System]. Guangdong: Guangdongsheng xinhua shudian.

Zhonggang, S. (2006). A Relevance Theory Perspective on Translating the Implicit Information in Literary Texts. Journal of Translation, 2(2), 43-60.

Zixia, C. (2009). A Cognitive-Pragmatic Model for Translation Studies Based on Relevance and Adaptation. Canadian Social Science, 5(1), 88-111.

\section{Copyright Disclaimer}

Copyright for this article is retained by the author(s), with first publication rights granted to the journal.

This is an open-access article distributed under the terms and conditions of the Creative Commons Attribution license (http://creativecommons.org/licenses/by/3.0/). 